\title{
Dust concentration in the urban environment air depending on traffic intensity and time of year (on the example of the Volgograd city)
}

\author{
D.R. Dobrinskiy ${ }^{1}$, D.A. Nikolenko ${ }^{2}, A . N$. Vasil'ev ${ }^{1}$, E.V. Gorshkov ${ }^{3}$ and V.N. Azarov \\ ${ }^{1}$ Volgograd State Technical University, 400301, Volgograd, Russia \\ ${ }^{2}$ Don State Technical University, 344002, Russia \\ ${ }^{3}$ All-Russian Research Institute of Environmental Protection, 344000, Russia
}

\begin{abstract}
Measurements of the small-dispersed dust concentration on 50 roads intersections in morning and evening, in winter and spring periods in the Volgograd city. A comparative analysis of the small-dispersed dust concentration in morning and evening is carried out, and the results, obtained in winter and spring, are compared. Methods to reduce dust emission from the roadway are proposed.
\end{abstract}

\section{Introduction}

Road transport has a significant impact on the air quality of urban environments around the world. The trend towards an increase in vehicle numbers on roads leads to a continuous deterioration in the air quality of the urban environment. The main pollution sources, along with exhaust gases and incompletely burned fuel, are the anti-icing mixture, present on the road surface in winter, as well as the abrasion products of organic binders that included in road surface and car tires. According to estimates, emissions from road transport into the city's atmosphere around $70 \%$.

For a comprehensive analysis of the environmental situation in the roadside Volgograd territories, dust measurements were taken in a period from 20.12.2018 to 30.01.2019 and from 26.03.2019 to 27.03.2019 in 9 Volgograd districts: Traktorozavodsky, Krasnooktyabrsky, Central, Dzerzhinsky, Voroshilovsky, Sovietsky, Kirovsky, Krasnoarmeysky and Gorodishchensky.

A research on ambient dust levels in the urban air was carried out at 50 major transport hubs in winter and spring, in the morning and evening. The main measuring points are shown in Fig. 1. For measurements, a high-tech handheld particle counter Handheld 3016 IAQ was used. The device allows measurements in six size ranges from 0,3 to 10 microns at a time. The data obtained were summarized in tables, according to which several diagrams and graphs were built. To assess air pollution at different points, at different times of the day and time of the year, the TPM indicator was used (total particulate matter). According to the instructions for the device, this value is the sum of the 6 values measured dust ranges. 


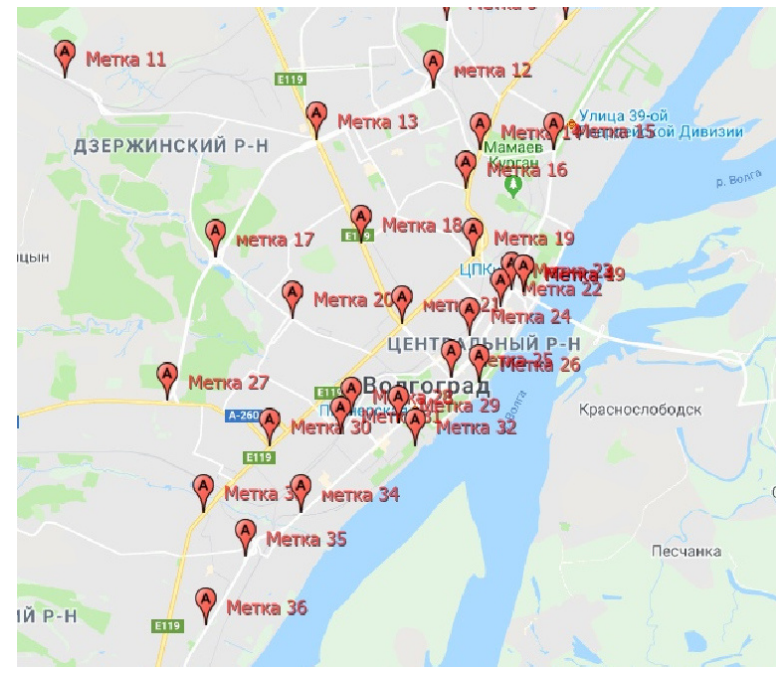

Fig. 1. The main measuring points on the satellite map of Volgograd.

Winter measurements were carried out in high humidity conditions, at a negative ambient temperature. Subjectively, there was no serious air pollution, which was confirmed by the measurement results. TPM values rarely rose above $100 \mathrm{mcg} / \mathrm{m}^{3}$, and the average value of all measurements was about $87 \mathrm{mcg} / \mathrm{m}^{3}$

\section{Results}

With the coming of spring and the snow cover disappearance, with the establishment of dry sunny weather, the measurements were repeated. In the period from the first decade of March, a stable dust suspension was observed on the city roads, with an increase in the dust concentration in the evening. TPM values ranged from $40 \mathrm{mcg} / \mathrm{m}^{3}$ to $2670 \mathrm{mcg} / \mathrm{m}^{3}$. The average evening measurements values were about $674 \mathrm{mcg} / \mathrm{m}^{3}$, which is more than 7,7 times higher than according to the winter measurements. It is worth adding that this value is an excess of the maximum permissible average daily concentration (MPC) of small-dispersed dust in the urban environment air, which is 4,5 MPC. Similar excesses are also found in a number of other cities in Russia. [3]. Figure 2 shows a chart of morning and evening TPM values measurements.

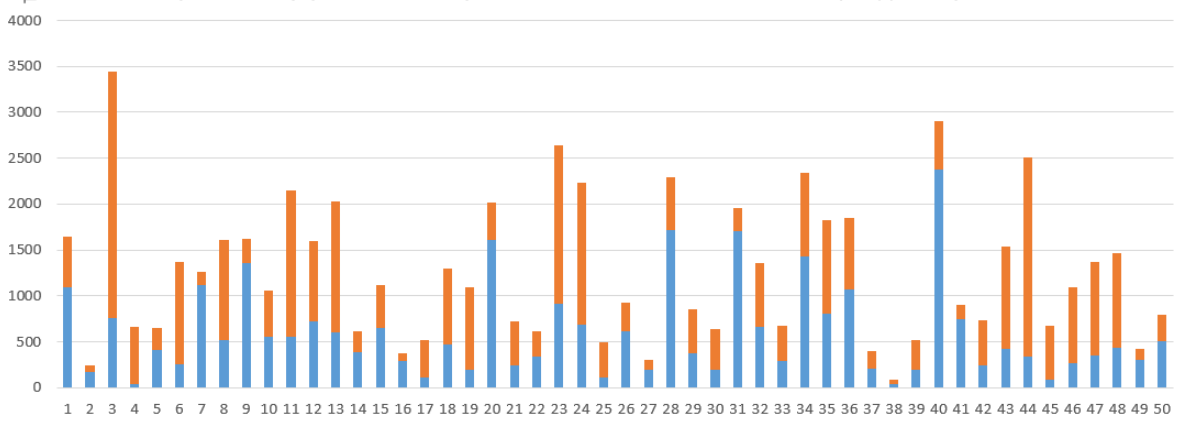

Fig. 2. Comparison TPM values of spring measurements in morning and evening.

As can be seen from the diagram in Figure 2, an increase in air pollution is observed at all evening measurement points compared to the morning period. Automobile transport 
throughout the day dispels dust in the air that has settled overnight on the roadway, resulting in its accumulation in the evening in the air with fixing maximum TPM values. The obtained values heterogeneity is also observed depending on the geographical location of the measuring point. For example, the point at number 2 has a low traffic intensity and is located at a considerable distance from the main city highways, just like the point at number 38 is 5 $\mathrm{km}$ from the heavily loaded 2 longitudinal highway and has extremely low intensity characteristics, resulting in data points recorded minimum values. On the contrary, the points at which the traffic intensity values are quite large, significantly higher TPM values are recorded. On Figure 3 shown the diagrams of the given values sum of all studied points directions intensity overlaid in the evening TPM values diagram.

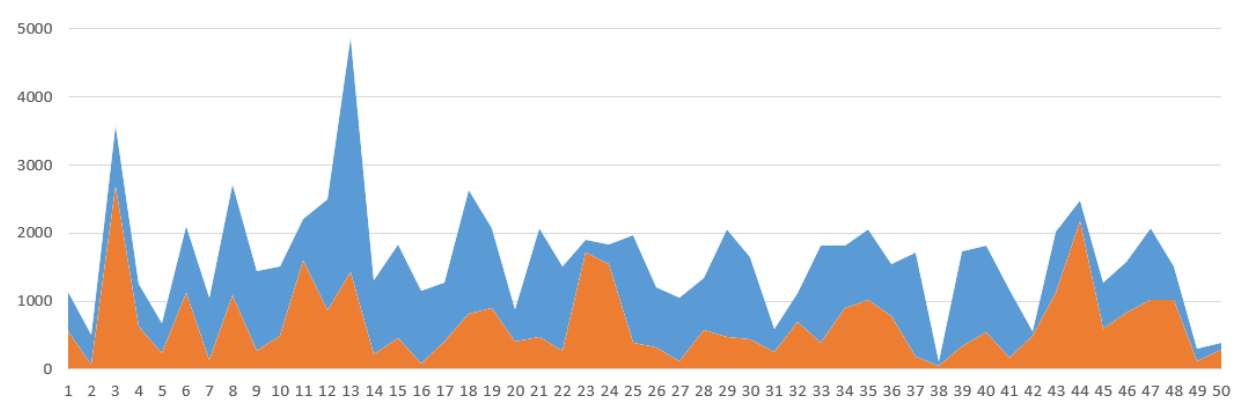

Fig. 3. The chart overlay of reduced traffic intensity on the TPM values chart.

Observing the diagrams in Figure 3, it can be easily noticed that the contours of both diagrams are largely similar and have characteristic peaks and dips in the reduced traffic intensity and dust concentration in air values, which suggests a certain dependence degree of air pollution on the automobile transport traffic intensity. 3000

Figure 4 shows the evening TPM values for winter and spring measurements.

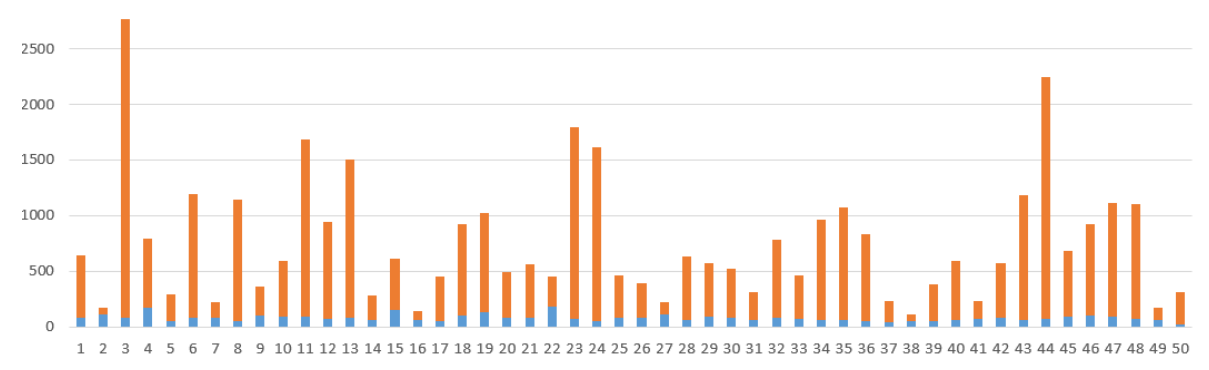

Fig. 4. Charts of TPM values for winter and spring measurements.

As shown in Figure 4. spring TPM values are bigger than winter ones. Most likely, this is due to the fact that in winter, at freezing temperatures and the presence of snow cover on areas adjacent to highways, dust components are connected by water and ice. Intensive road surface sanding with reagents in the winter season leads to the accumulation of silicon dust small particles on the road surface, curbs, adjacent sidewalks, and green areas. As soon as dry weather is established at a positive ambient temperature, dust particles are released due to the vehicles passage and wind gusts, resulting in an increase in the small particles concentration in the air of an urban environment. For a more detailed small-dispersed dust, it is necessary to perform a disperse analysis in accordance with GOST R 56929-2016. [4] Having studied the existing dust removal methods of road coatings, it can be concluded, that one of the most effective methods is the cleaning with usage a material based on waterorganic emulsions with a simple technology for its preparation and application. The main 
advantages of this method, in comparison with the humidification methods, introduction of chemical solutions and the bottling of bitumen emulsions, are its low unit cost and the actual effect duration. (Table 1)

Table 1. Comparison of dust removal methods

\begin{tabular}{|l|l|l|l|l|}
\hline \multirow{2}{*}{$\begin{array}{l}\text { Comparison } \\
\text { indicator }\end{array}$} & \begin{tabular}{l} 
Dust removal methods from roads \\
\cline { 2 - 5 }
\end{tabular} method & $\begin{array}{l}\text { Hydration } \\
\text { with water }\end{array}$ & $\begin{array}{l}\text { Introduction of } \\
\text { chemical } \\
\text { solutions }\end{array}$ & $\begin{array}{l}\text { Bottling of } \\
\text { bitumen } \\
\text { emulsions }\end{array}$ \\
\hline $\begin{array}{l}\text { Consumption } \\
\text { of material, } \\
1 / \mathrm{m} 2\end{array}$ & $0,5 . .0,8$ & $5 . .8$ & $1,5 . .2 .0$ & $1,5 . .2,0$ \\
\hline $\begin{array}{l}\text { The effect } \\
\text { duration, day }\end{array}$ & up to 80 & up to 0,2 & up to 10 & up to 60 \\
\hline $\begin{array}{l}\text { Estimated } \\
\text { work cost, } \\
\text { thousand } \\
\text { rubles/km }\end{array}$ & 96 & 20 & 35 & 185 \\
\hline
\end{tabular}

Chemically, the emulsion has macromolecules with a chain fibrillar form with a relatively low cohesion and high adhesive ability. The usage of cationic surfactants can reduce the dust particles wetting angle and increase their hydrophilization. The increased wetting effect is achieved due to the paraffin-naphthenic and aromatic hydrocarbons content, which are contained in organic substances (oil and its processing products).

\section{Conclusions}

To summarize, the described dust removal method for automobile roads allows to solve the following problems:

- reduction of dust levels close to agricultural land roads;

- decrease in the respiratory diseases level;

- improving traffic safety by reducing the dust cloud formation level during the vehicles movement on career and dirt roads;

- decrease in costs for dust removal of roads actions.

\section{References}

1. N.S. Barikaeva, Improving the air pollution monitoring system of cities roadside territories with small-dispersed dust, 2017.

2. V.N. Azarov, Bulletin of the Volgograd State University of Architecture and Civil Engineering. Ser.: Construction and architecture, 25 (44), 398-401 (2011).

3. M.V. Grafkina, E.E. Sdobnyakova, Bulletin of Moscow State University of Mechanical Engineering (MAMI), 3 (21), 65-70 (2014).

4. V.N. Azarov, A.V. Kovaleva, N.M. Sergina, Int. conf. "Environmental safety and economics of urban and heat power complexes", VSTU, 76-78 (1999).

5. S.N. Shabaev, M.V. Sokolov, A.R. Amanbakiev, The use of water-organic emulsion for roads dust removal of Kuzbass, IX All-Russian scientific-practical conference of young scientists "RUSSIA YOUNG", 2017. 